\title{
Contribuciones de Zamorano a la Investigación y Proyección en el Manejo de Cuencas en Centro América
}

\author{
Luis A. Caballero B. ${ }^{1}$
}

\begin{abstract}
Resumen. El agua es el bien y servicio ecosistémico más valorado por las poblaciones rurales y urbanas. Dada su importancia en la vida cotidiana del ser humano, el agua y las cuencas presentan oportunidades únicas para promover un modelo de manejo integrador, incluyendo lo ambiental, socioeconómico e institucional. Es en la cuenca donde el interés individual de usufructuar la tierra para beneficio y ganancia personal y familiar, tiene que sopesarse con el interés público de obtener agua de calidad, en cantidad apropiada y con regularidad. Hay zonas en las cuencas en donde la protección y conservación del bosque es imprescindible para la producción y provisión sostenida de agua. En los últimos 18 años, el programa de manejo de cuencas de Zamorano, con apoyo financiero de varios entes nacionales e internacionales, ha contribuido a la protección de los recursos naturales en importantes cuencas de la región. El programa ha también beneficiado miles de familias mediante la reconstrucción y construcción de sistemas de agua para riego agrícola y consumo humano. Miles de jóvenes rurales fueron capacitados e involucrados en la protección de los recursos naturales y actividades de desarrollo local. Además, centenas de jóvenes latinoamericanos se han graduado de Zamorano, y están hoy día activamente involucrados en manejo de cuencas, la protección de los recursos naturales y el desarrollo rural a través de Latino América. La investigación aplicada, desarrollada por profesores y estudiantes de la Carrera de Desarrollo Socioeconómico y Ambiente (DSEA), permitió conocer mejor los escenarios de trabajo. Esto ayudó a la planificación e implementación de acciones más precisas y efectivas, y a monitorear y evaluar los programas y proyectos. La contribución de Zamorano al avance de la ciencia hidrológica en el trópico incluye el diseño y construcción de dos sitios de investigación que son cuencas experimentales: Capiro-Zapotillo y el Parque Nacional la Tigra. Todos estos programas y proyectos han contribuido muchoa las comunidades rurales y a la sociedad en general.
\end{abstract}

Palabras clave: Bosques nublados, cuenca experimental, hidrología, irrigación, manejo de cuencas, recursos hídricos.

\section{Zamorano's Contributions to Research and Outreach in Watershed Management in Central America}

\begin{abstract}
Water is the most valued good and ecosystem service, by both rural and urban populations. Given its importance to the daily life of human being, water and watersheds provide unique opportunities to promote an integrated model of management including environmental, socio-economic and institutional aspects. It is in the watershed that the individual interest to use land for personal or family gains, has to be weighted with the public interest of obtaining water in good quality, quantity and on a regular basis. There are zones in the watershed in which the protection and conservation of the forest cover is critical for the sustained provision of water. In the last 18 years Zamorano's watershed management program, with financial support from several national and international donors, has contributed to the protection of natural resources in important watersheds in the region. The program has also benefitted thousands of families through the re-construction and construction of water supply systems, both for irrigation and human consumption. Thousands of young people from rural areas have been trained and participated in natural resources protection and local development activities. Furthermore, hundreds of LatinAmerican youths (both women and men) have graduated from Zamorano and are now actively involved in watershed management and rural development across the region. Applied research conducted by professors and students from the Environment and Development Program has provided a better understanding of local work scenarios. This has aided in the planning and implementation of more precise and effective actions, to monitor and evaluate programs and projects. Zamorano's contribution to the advancement of hydrological sciences in the tropics includes designing and constructing two experimental catchments Capiro-Zapotillo y La Tigra National Park. All of these programs and projects have made a significant contribution to rural communities and to society in general.
\end{abstract}

Key words: Cloud forest, experimental watershed, hydrology, irrigation, watershed management, water resources.

${ }^{1}$ Profesor Asociado, Manejo de Cuencas/SIG y Ciencia Ambiental. Departamento de Ambiente y Desarrollo. Escuela Agrícola Panamericana, Zamorano, Honduras, correo electrónico lcaballero@zamorano.edu

DOI: $10.5377 /$ ceiba.v52i1.974 


\section{Introducción}

Desde su fundación en 1942, la Escuela Agrícola Panamericana ha aplicado estrategias, programas, planes de manejo y protección de las cuencas que la abastecen con agua para su funcionamiento y desarrollo, así como a las comunidades vecinas. Es así que la Reserva Biológica Uyuca (RBU), por más de 60 años ha sido la fuente principal de agua para consumo humano, riego agrícola y procesamiento agroindustrial. Además, ha servido para la educación y entrenamiento práctico de más de 60 promociones de graduados que hoy contribuyen a la protección sostenible de los recursos forestales y las cuencas en Latino América.

La formación académica y la proyección en Gestión y Manejo Integral de Cuencas (GMIC) comenzaron como parte de programa académico en 1993 con la creación del Departamento de Recursos Naturales y Conservación Biológica (DRNCB). En un inicio (1993-1994) fue liderado por el Dr. Jay M. Hughes, fiduciario de Zamorano, y por el Dr. George Pilz (1994-1999), con quien se iniciaron los primeros proyectos de manejo de microcuencas (PROCUENCAS). En 1999, como parte del programa $4 \times 4$ (cuatro carreras y cuatro años), se formó la Carrera de Desarrollo Socioeconómico y Ambiente (DSEA), con la unión del DRNCB y el Departamento de Desarrollo Rural (DDR). Esta carrera fue inicialmente liderada por el Ing. Peter Doyle (19992003), quien consolidó un equipo multidisciplinario de expertos y expandió las intervenciones de manejo de cuencas en la región con apoyo financiero de USAID. Luego, DSEA fue liderada por la Lcda. Mayra Falck (2004-2007, y últimamente por el Ing. Arie Sanders (2008 al presente), misma que tomó el nombre de Departamento de Ambiente y Desarrollo (DAD) en el 2012.

Zamorano, con el apoyo de organismos de desarrollo internacional y gobiernos, ha ejecutado varios proyectos durante los últimos 18 años enfocados al manejo de cuencas, recursos hídricos y desarrollo rural. Estos proyectos han contribuido en forma directa e indirecta a la protección integral de las cuencas y los recursos naturales de la región. Los proyectos han capacitado y transferido las tecnologías y los conocimientos a los miembros de las comunidades y técnicos del sector público y no gubernamental. Estos proyectos han permitido la formación práctica de los estudiantes de Zamorano por medio del desarrollo de módulos del aprender haciendo en las comunidades, así como oportunidades de estudio-trabajo. Además, los estudiantes, mediante la investigación aplicada y con el asesoramiento de profesores y técnicos de campo, han contribuido a mejorar la toma de decisiones y la evaluación de los impactos de los proyectos.

El agua es el bien y servicio ambiental, generado en las cuencas hidrográficas y sus aéreas protegidas, más sentido por la población. Dada la importancia del agua en la vida cotidiana de las comunidades rurales y urbanas, ésta presenta oportunidades únicas para promover un modelo de manejo de cuencas integrador, en lo ambiental, socioeconómico e institucional. Es en la cuenca donde el interés individual de usufructuar la tierra para beneficio familiar, tiene que sopesarse con el interés colectivo de protegerlas junto con sus bosques para obtener suficiente agua de calidad y con regularidad.

El modelo de planificación para la gestión integral de cuencas en Zamorano se desarrolló tomando en consideración esas premisas, por lo tanto, se propuso un enfoque basado en el escalamiento territorial desde la finca como unidad familiar, pasando a la comunidad, a la microcuenca, subcuenca, mancomunidad, cuenca y país (Figura 1). Este enfoque facilitó el trabajo cooperativo entre diversos actores o grupos de interés, haciendo más participativa la toma de decisiones, y por ende más efectivo el manejo y los impactos de las intervenciones. Todo lo anterior fue, y es necesario, con el fin de asegurar a largo plazo la estabilidad de la cuenca en la provisión de los servicios ecosistémicos belleza escénica, aire, biodiversidad, el agua, y la reducción de vulnerabilidad a deslizamientos, sequías e inundaciones.

El modelo de planificación e intervención a diferentes escalas territoriales y sociales permite un diálogo más amplio y la coordinación entre actores. Lo anterior es para favorecer los usos complementarios del territorio, mientras se previene y minimizan los conflictos de interés por el uso de las tierras que afectan los recursos naturales, y a largo plazo la estabilidad ecológica e hidrológica de la cuenca. 


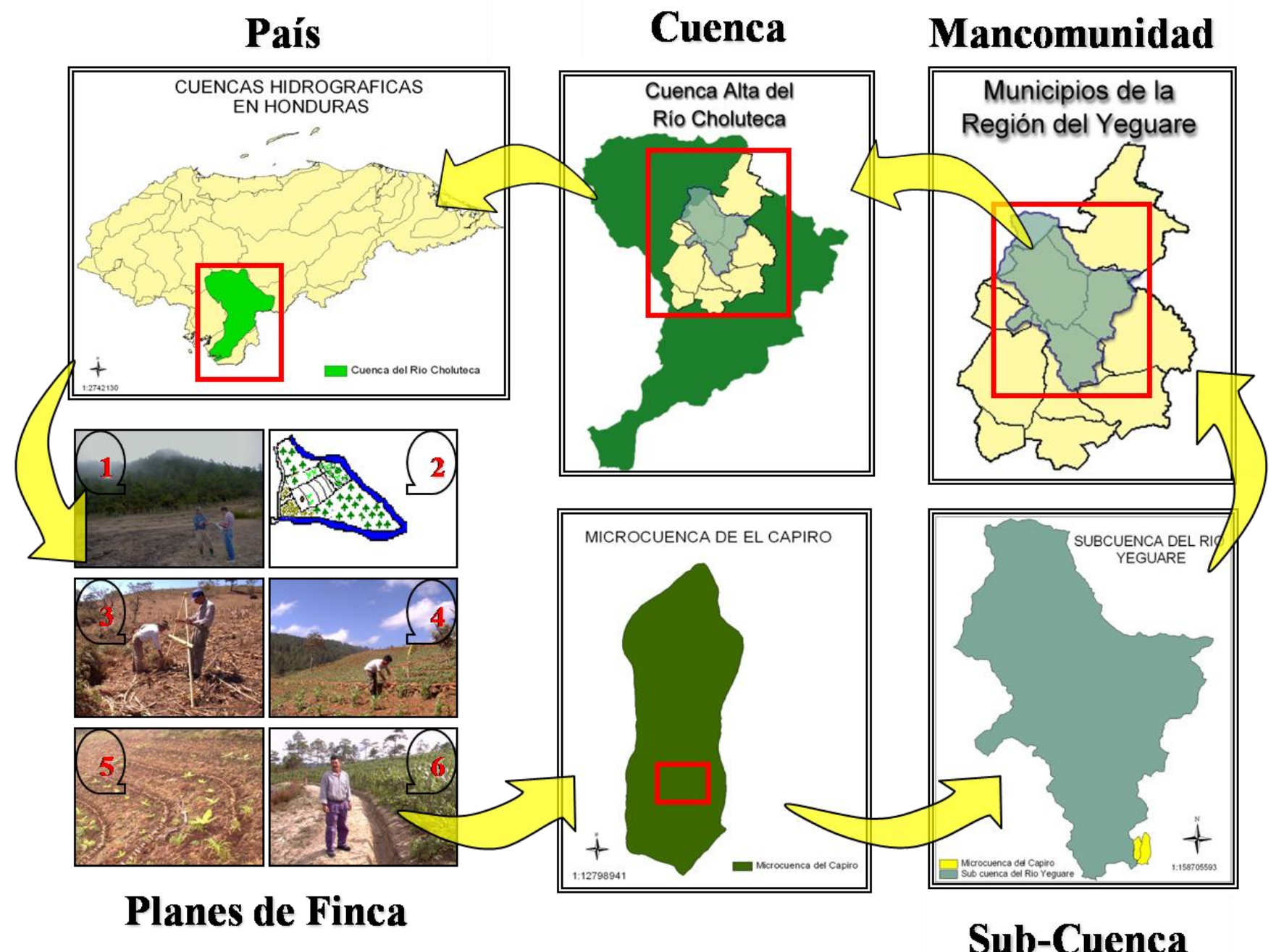

Figura 1. Modelo de planificación con enfoque territorial del manejo de cuencas para favorecer el aprendizaje incremental y acumulativo con los actores locales, instituciones y agencias gubernamentales y entes de financiamiento, (1-6 denota los pasos del proceso de intervención desde fincas hasta regiones y país).

Zamorano, con el apoyo de entidades financieras nacionales e internacionales (Gobierno HondurasCanadá-Fundación Vida, BCIE, Fundación W.K. Kellogg, CLUSA)/USAID, FUPAD/USAID, UWRDAI/USAID, USAID/Zamorano, MIRA/USAID/ Zamorano, PREVDA/EU/Zamorano, desarrolló los proyectos que a continuación se describen:

Fundación Vida-PROCUENCAS I. El proyecto se ejecutó en 1996 con fondos del Canje de Deuda Externa Honduras-Canadá, ejecutado por la Fundación
Vida y coordinado por el Ing. Carlos Ardón. Las acciones se enfocaron al manejo sostenible de los recursos naturales en los municipios de San Antonio de Oriente, Maraita y Güinope. Las actividades más importantes ejecutadas fueron: i) la construcción de estufas mejoradas para reducir el consumo de leña y mejorar la salud en los hogares; ii) el establecimiento de plantaciones dendroenergéticas para reducir la presión de la extracción de leña de los bosques naturales; iii) la protección de los bosques contra los incendios; iv) la protección y la restauración de las 
zonas de recarga hídrica de las fuentes de agua comunitaria mediante prácticas de conservación de los suelos y el agua. Además, se organizaron y capacitaron brigadas comunitarias para la prevención y combate de incendios. También se organizaron y capacitaron grupos de jóvenes, líderes locales y clubes de amas de casa para mejorar los hogares. Este proyecto también sirvió de base para la planificación y ejecución del proyecto Procuencas II.

\section{PROCUENCAS II (Fondo Medio Ambiente}

Honduras-Canadá). Este proyecto duró dos años (1997-1998). Los fondos provinieron de las contribuciones del Fondo de Medio Ambiente Honduras-Canadá, las aportaciones institucionales y de las comunidades participantes. El área de influencia del proyecto fueron las microcuencas Capiro-Zapotillo en Güinope, El Paraíso y comunidades del municipio de Maraita, Francisco Morazán. Las acciones más relevantes fueron la promoción de las estufas mejoradas, el establecimiento de parcelas dendroenergéticas, la implementación de prácticas agrícolas sostenibles en microcuencas con estados avanzados de deforestación (Figura 2), dentro de ellas: conservación de los suelos y el agua, introducción de variedades mejoradas e investigación aplicada, la promoción de cultivos agroforestales (Figura 2), programas de educación ambiental en centros educativos y la formación de grupos comunitarios para la prevención y el control de incendios forestales. Durante este proyecto se realizaron los primeros diagnósticos sobre la situación de los recursos naturales de dichos municipios. Además, se generó material didáctico que sirvió como material educativo en los programas y proyectos que le prosiguieron.
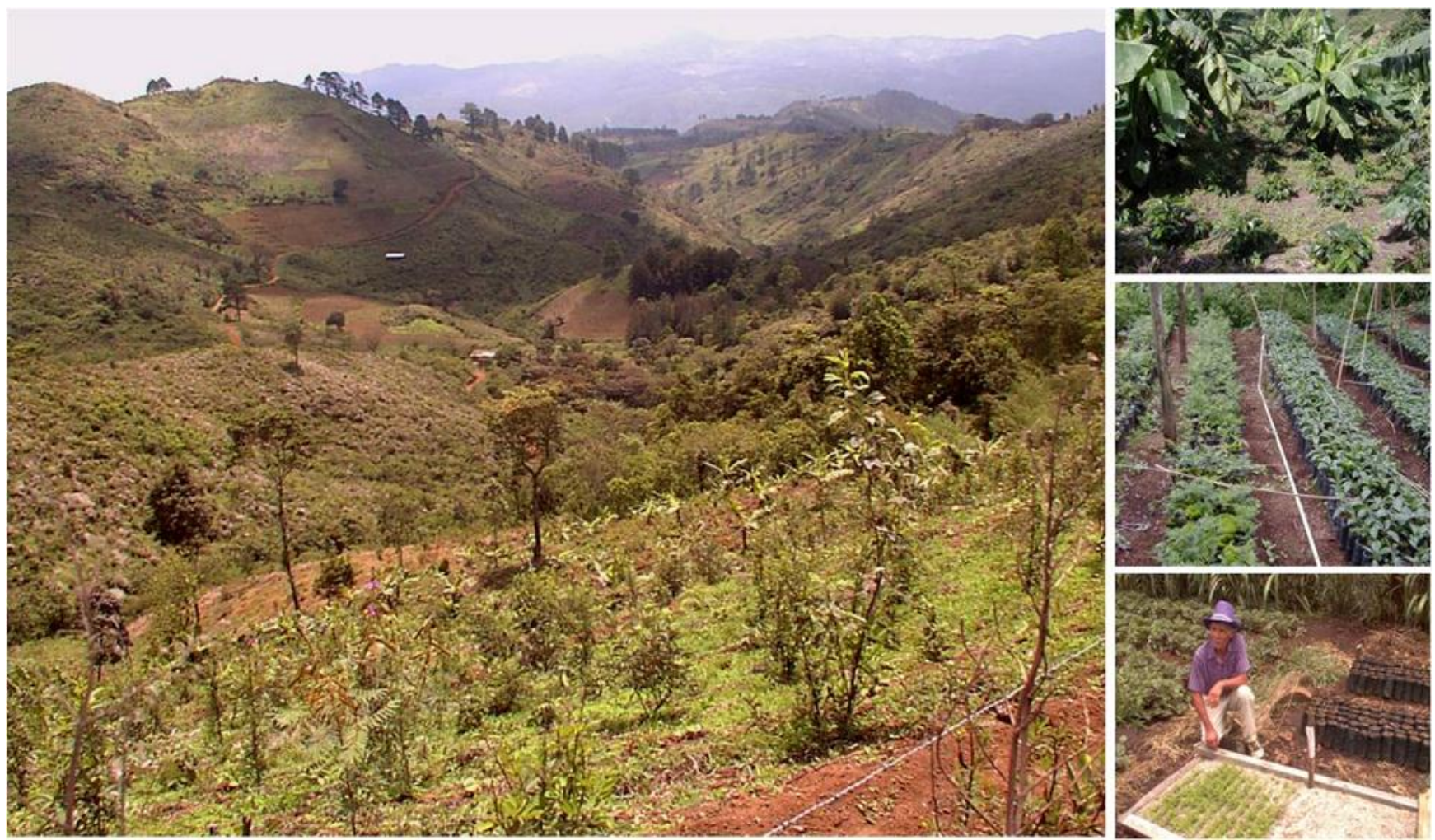

Figura 2. Ejemplos de las condiciones de degradación de la cubierta forestal en la microcuenca El Capiro, Güinope, El Paraíso (foto de la izquierda), y primeros pasos de la restauración con sistemas agroforestales de café (fotos de la derecha) promovidos por PROCUENCA II/Zamorano. 
Proyecto Bambú. Fue gestionado y liderado por el Dr. Eduardo Aguilar y apoyado en la ejecución por la Arq. Nelly Falck en el Depto. de Planificación y Construcción de Zamorano. El dinero provino del Banco Centroamericano de Integración Económica (BCIE). El resultado más importante fue la creación de una de las colecciones más completas de bambú en Latino América, cuenta con especies rescatadas de Zamorano y otras del jardín botánico de Lancetilla, a donde llegaron en los años 40 como contribución del Saint Louis Botanical Garden. Otras especies procedían de Chocolá y Mocá en Guatemala, del Proyecto Nacional del Bambú de la Escuela de Agricultura de la Región del Trópico Húmedo (EARTH) en Costa Rica, y de exploraciones botánicas en Honduras. Esta colección está distribuida en varias zonas del campus y forman parte del Arboretum Simón E. Malo en Zamorano. Los usos son como reserva de germoplasma para la investigación y la educación de los estudiantes, protección y restauración de las riveras de los ríos, y la industria de la construcción. Según el Arq. Eduardo Aguilar, en el pasado se investigó sobre la construcción con bambú, sobre todo en métodos de tratamiento de preservación. También se investigó el desarrollo de un método más sencillo, práctico y eficiente que el llamado "Boucherie", desarrollado en Indochina hace varias décadas por investigadores franceses.

Proyecto UNIR. Fue financiado por la Fundación W.K. Kellogg y el aporte institucional de Zamorano, fue ejecutado entre 1996 y 1999 bajo el liderazgo del Dr. Eduardo Aguilar, Jefe de Diseño y Construcciones. Incorporó a los profesores y estudiantes de Zamorano a través de la investigación aplicada y la transferencia de conocimiento agrícola, pecuario y de la conservación y manejo de los recursos naturales. El proyecto trabajó en 72 aldeas de los municipios de San Antonio de Oriente, Yuscarán, Tatumbla, Morocelí, Güinope y Maraita. Sus actividades se enfocaron en fortalecer las capacidades de los gobiernos locales y organizaciones comunitarias para la promoción del desarrollo sostenible de la región del Yeguare. Entre las actividades más importantes están el programa de manejo de los recursos naturales que incluyó la promoción y la adopción de prácticas de manejo sostenible del bosque, protección de las fuentes de agua, actividades de producción agrícola, conservación de suelos, mejoramiento de los hogares, salud y educación rural y el desarrollo microempresarial. Otros logros son:

- Un mapeo regional y base de datos socioeconómicos y geográficos, con participación comunitaria, de la Región del Yeguare; incluyó más de 10,000 datos complementado con imágenes satelitales LANDSAT TM y la aplicación de imágenes satelitales SAR RADARSAT. Con ello se creó un catálogo digital de mapas temáticos a partir de los daños ocasionado por el huracán Mitch en la región.

- La organización, motivación y capacitación de más de 2,000 personas en la prevención y combate de los incendios forestales que redujo 87\% el área quemada entre 1997 y 1999.

- Apoyo a la producción comercial de especies forestales y la capacitación en viveros, en Chagüite Belén, El Ocotal y Los Limones, Municipio de Yuscarán. Con treinta familias, entre 1997 y 1998, se produjeron 80,000 plántulas y generó a los participantes un ingreso de L. 160,000.

- Capacitaron líderes comunitarios en la producción comercial de especies forestales y construcción de viveros. Se produjeron 90,000 plántulas y se involucraron 200 personas de El Jicarito y El Llano del Ocotal, San Antonio de Oriente, Morocelí y Yuscarán. El programa incluyó la participación de un colegio y una escuela de la cabecera municipal de Yuscarán.

- Capacitación en la planificación y manejo participativo de microcuencas que abastecen de agua potable a las comunidades.

- Estudio de uso de la leña en la región del Yeguare, con el apoyo de Catrin Schreiber de la Universidad Humboldt de Berlín y el Proyecto GTZ-EAP Zamorano

Entre sus logros importantes destacan la creación de la Asociación de Mancomunidad de Municipios de la Región del Yeguare (seis) y la creación de un "cluster" de turismo agrorural. Además, se apoyó la salud y capacitación de jóvenes para su incorporación a la vida productiva rural y la formación de alianzas entre los actores locales (Aguilar y Ramirez, 2000). 
Proyecto rehabilitación y manejo de cuencas en Nicaragua. El proyecto fue ejecutado entre 1999 y 2001 por la Carrera de Desarrollo Socioeconómico y Ambiente mediante un acuerdo de cooperación con la Liga de Cooperativas de Estados Unidos (CLUSA)/USAID) (DSEA, 2001). El propósito del proyecto fue desarrollar capacidades para el manejo y la rehabilitación de las cuencas afectadas por el huracán Mitch en las subcuenca del Río Negro, Estero Real y Estelí, Nicaragua. El equipo de trabajo fue dirigido por el Ing. Peter Doyle, Jefe de DSEA y el Ing. Robert Walle, gerente técnico. Los resultados más relevantes son: la protección y la restauración de las riveras de los ríos (Figura 3) para reducir la vulnerabilidad a las inundaciones y los daños a la infraestructura de los caminos y el tendido eléctrico. También se apoyó la rehabilitación y la construcción de sistemas de agua, la protección de zonas de recarga hídrica a través de la conservación de suelos y aguas, el mejoramiento de los cultivos y la capacitación de los productores agrícolas y los actores locales en manejo de cuencas en coordinación con DANIDA. Este proyecto se premió como finalista en el concurso mundial de recursos hídricos en el Tercer Foro Hídrico Mundial realizado en marzo del 2003 en Kyoto, Japón.
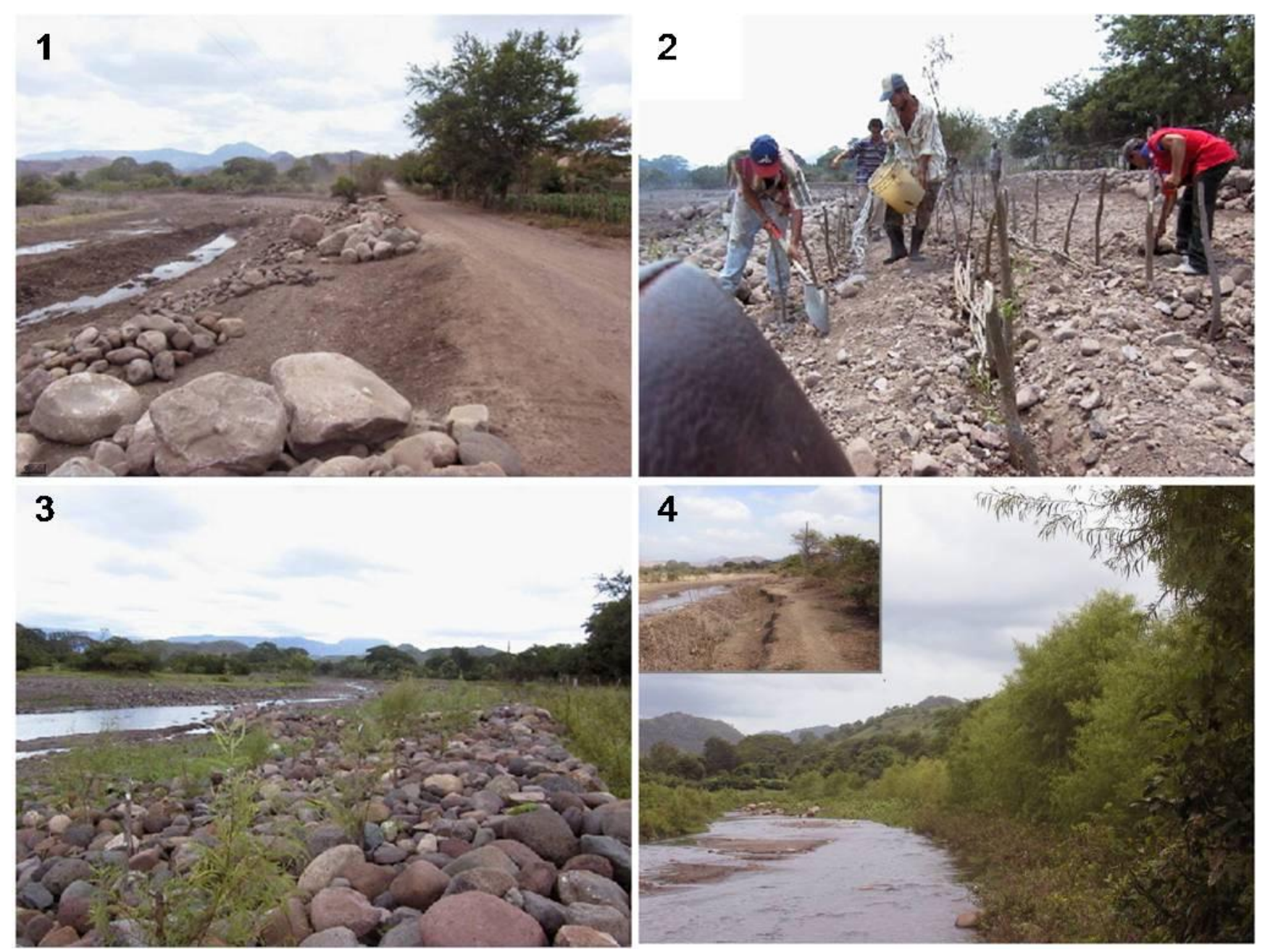

Figura 3. Ejemplo del trabajo de restauración (1-4 pasos del proceso) de la riveras de los ríos para la reducción de la vulnerabilidad desarrollados en Estelí, Nicaragua, 2001 (Trabajos y fotos del Ing. Robert Walle/Zamorano). 
Proyecto fortalecimiento local y planificación de manejo de cuencas (FUPAD). El proyecto fue ejecutado en el 2000 por la Carrera de Desarrollo Socioeconómico y Ambiente (DSEA 2000) mediante acuerdo de cooperación con la Fundación Panamericana para el Desarrollo (FUPAD/USAID). El propósito fue fortalecer las capacidades de los gobiernos locales y las organizaciones comunitarias de los municipios de La Libertad, Depto. de Comayagua; San Antonio de Oriente, Depto. de Francisco Morazán; y Morolica, Depto. de Choluteca. En San Antonio de Oriente y Morolica se capacitó en elaboración de proyectos para acceder a fondos de restauración pos Mitch. En La Libertad, Comayagua, se elaboró un plan de manejo para dos microcuencas afectadas por el huracán Mitch. Como resultados del proyecto ejecutaron 13 talleres de capacitación en la planificación del manejo de cuencas, con la participación de 267 productores y los miembros de las juntas de agua de 15 comunidades, 35 líderes comunitarios, dos funcionarios de la Unidad Municipal Ambiental (UMA) y los representantes de FUNBANCAFE, entre otros organismos de desarrollo. Lo anterior resultó en la elaboración de los planes de manejo de las microcuencas de los ríos Frío y Salitroso.

Adicionalmente, se capacitaron 20 actores claves en la formulación de propuestas de proyectos, lo cual permitió la consecución de fondos para nuevos proyectos de desarrollo y rehabilitación de la infraestructura dañada por el huracán Mitch. También se organizó y se capacitó a un grupo con 29 productores de café con orientación a la producción de café orgánico y cafés especiales (DSEA, 2000).

Proyecto rehabilitación y manejo mejorado de recursos naturales en la cuenca alta del río Choluteca (UWR-DAI/USAID). Este proyecto fue ejecutado entre octubre de 2000 y diciembre de 2001 y coordinado por la Carrera de Desarrollo Socioeconómico y Ambiente (DSEA), bajo el liderazgo del Ing. Peter Doyle. El financiamiento provino de un acuerdo de donación (\# UWR-006) entre Development Alternatives Inc. (DAI)/USAID y Zamorano. El proyecto se ejecutó en conjunto con las municipalidades de San Antonio de Oriente, Tatumbla, Güinope, Yuscarán, Maraita, Morocelí, Yauyupe, San Lucas y Oropolí. El aporte económico se complementó con el aporte institucional y local. Se promovieron e implementaron actividades en cuatro componentes interrelacionados: el manejo de los recursos naturales (coordinado por el Dr. Pilz), la agricultura sostenible, la rehabilitación de las cuencas (coordinado por el Dr. Luis Caballero) y el fortalecimiento ambiental municipal (coordinado por el Dr. Eduardo Aguilar). Los resultados del proyecto incluyeron a 677 productores con 607 ha de tierra bajo prácticas de manejo y conservación de los suelos y el agua (Figura 4). Además, se capacitaron 718 productores y se elaboraron e implementaron 112 planes de manejo de fincas.

El proyecto organizó, capacitó y equipó a 78 grupos con 649 participantes comunitarios para la prevención y el control de los incendios forestales y se elaboraron tres planes de manejo forestal en Maraita y San Antonio de Oriente. Se implementaron 83 proyectos comunitarios en las zonas afectadas por el huracán Mitch que incluyeron: la rehabilitación de los caminos rurales, la reconstrucción de los sistemas de agua (obras de captura, conducción y tanques de distribución), la protección de las zonas de recarga hídrica, pequeños proyectos de irrigación, la instalación de sistemas ecológicos de procesamiento del café y el manejo de las aguas residuales. También se elaboraron, en forma participativa, 25 planes de manejo de microcuencas mediante la aplicación de los enfoques y las técnicas modernas de la gestión integral de las cuencas y el monitoreo de la calidad del agua.

Se fortalecieron las capacidades de los gobiernos locales que incluyó la formación de ocho UMA y el fortalecimiento de una de las existentes. Se capacitaron 464 miembros de las UMA y líderes comunitarios para una efectiva gestión ambiental. Con el fin de promover el buen desempeño ambiental de la región del Yeguare, se creó una alianza intermunicipal que a futuro conduciría a la formación de la mancomunidad de municipios de la región del Yeguare (con nueve municipios). Al final del proyecto se beneficiaron, en forma directa, a más de 30,000 personas (DSEA, 2001). 


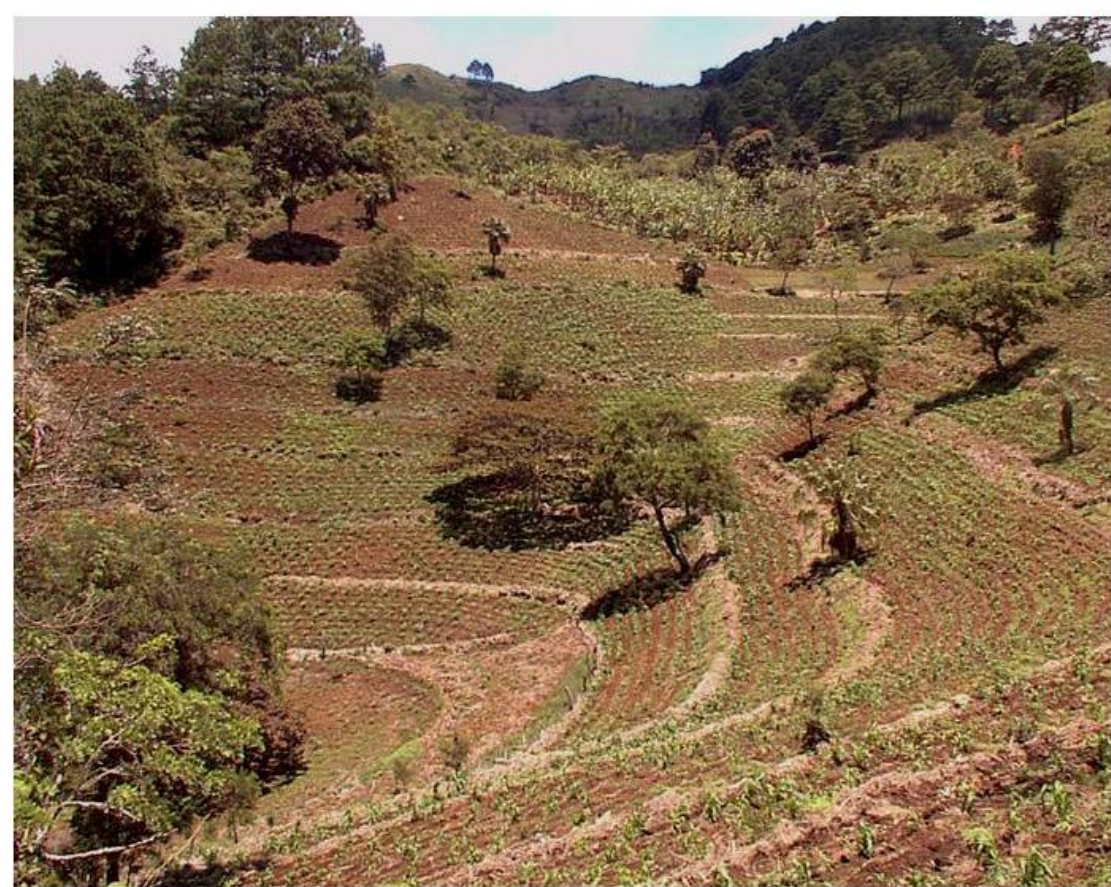

\section{Elaboración e Implementación de Planes de Finca}

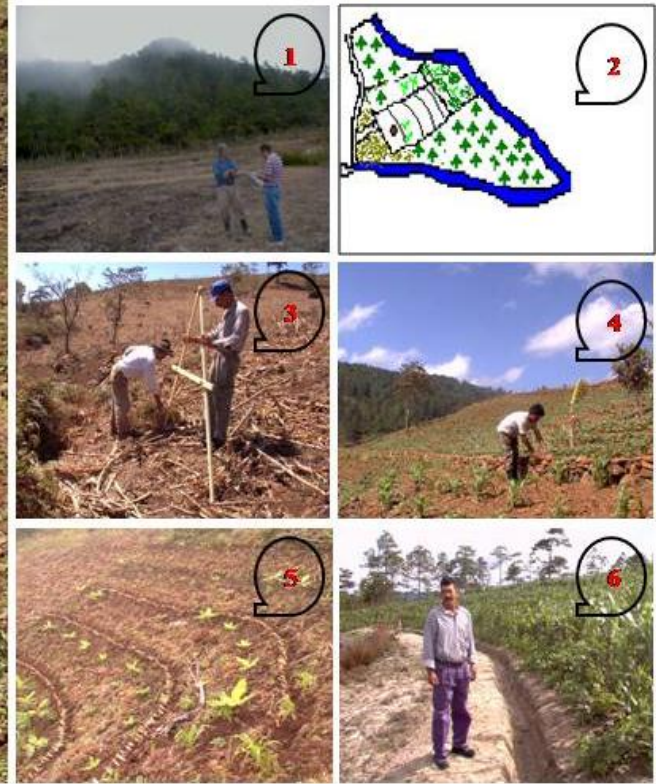

Figura 4. Foto de la microcuenca (izquierda). Implementación de prácticas de conservación y manejo de suelos y agua (1-6 denota el proceso), como parte de los planes de manejo de fincas y bajo el enfoque de manejo de las microcuencas, Capiro-Zapotillo, municipio de Güinope, Francisco Morazán, Honduras.

Manejo de Recursos Hídricos en la Cuenca Baja del Río Choluteca y Negro (USAID). Este proyecto fue ejecutado entre octubre 2003 y diciembre 2004 por la Carrera de Desarrollo Socioeconómico y Ambiente, bajo el liderazgo de la Licda. Mayra Falck (Directora de DSEA) y el Dr. Luis Caballero como gerente técnico. El proyecto fue financiado mediante el acuerdo cooperativo \#522-A-00-03-000420-0 entre USAID y Zamorano (DSEA 2005). El área de influencia fue de $991 \mathrm{~km}^{2}$ en las cuencas bajas de los ríos Choluteca y Negro e incluyó a los municipios de Choluteca, Marcovia, Namasigüe, El Triunfo, Orocuina, Apacilagua, El Corpus, Santa Ana de Yusguare y Concepción de María. El propósito del proyecto fue generar experiencias para el manejo participativo, eficiente y sostenible de los recursos hídricos mediante el fortalecimiento de las capacidades locales.

El proyecto se ejecutó en tres áreas temáticas interconectas i) prácticas y tecnologías eficientes del uso del agua, ii) mejoramiento de los marcos políticos y legales para el manejo del agua iii) estudios técnicos en apoyo a la planificación y la ejecución de acciones de campo. Las acciones de campo se implementaron a través de pequeños proyectos de inversión compartida con los actores locales con el fin de incrementar el acceso a agua para el consumo humano (Figura 5) y optimizar su uso productivo para riego agrícola. Al mismo tiempo se desarrollaron actividades para incentivar e incrementar la conciencia y la participación del público para una mejor gobernanza del sector agua (Walle, 2004).

En el componente de las prácticas y las tecnologías eficientes del uso del agua se implementaron mejores prácticas de manejo (BMP) en 220 ha de tierra y se instalaron 74 proyectos de irrigación que beneficiaron a 142 familias (Figura 6). La mayoría de estos proyectos se enfocaron en la construcción o la reconstrucción de las obras de captura, las líneas de conducción y distribución con énfasis en los sistemas de riego por goteo. 

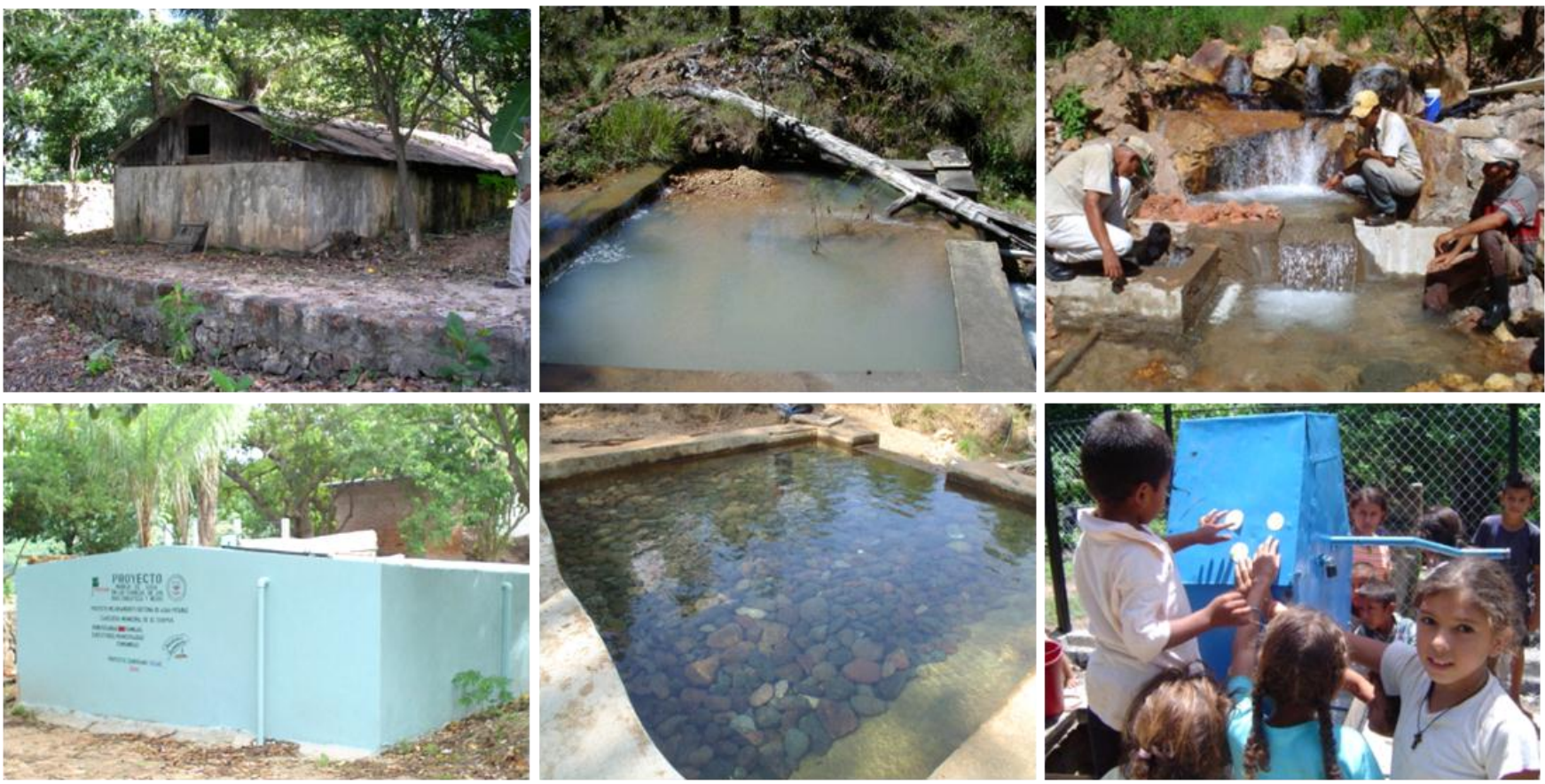

Figura 5. Algunos ejemplos de sistemas de agua potable reconstruidos y mejorados (foto arriba condición inicial, fotos abajo condición final) en la cuenca baja del Río Choluteca y Negro. Proyecto Manejo de Recursos Hídricos en la cuenca baja de los ríos Choluteca y Negro Zamorano/USAID (DSEA, 2005).
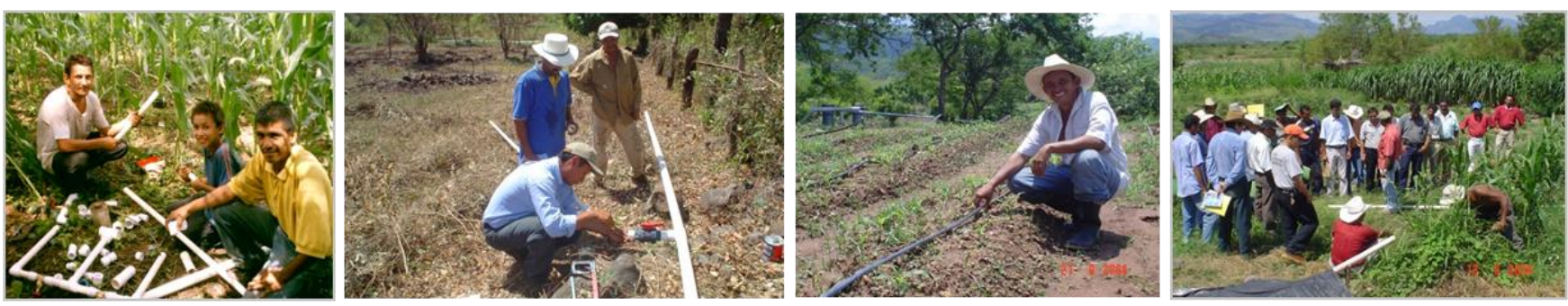

Figura 6. Capacitación en las parcelas demostrativas de riego eficiente para pequeños productores, con el fin de asegurar la producción al presentarse lluvias irregulares y así reducir la vulnerabilidad ante el cambio climático en la cuenca baja del río Choluteca, Honduras.

Además, se construyeron seis reservorios pequeños para capturar y la conservar el agua en zonas productivas para prolongar su acceso durante los periodos críticos y asegurar la producción agrícola. Dichas estructuras tienen una capacidad de almacenamiento de $39,000^{3}$ de agua para el beneficio de 76 familias (Figura 7).

Además de la construcción de las obras demostrativas, se capacitaron 409 finqueros (330 hombres y 70 mujeres) y 49 técnicos del gobierno local, de organizaciones no gubernamentales y del sector privado que trabajaban en el manejo del agua. La capacitación se enfocó en i) los conceptos básicos de la irrigación, ii) la instalación y el mantenimiento de los sistemas de irrigación, iii) el manejo eficiente del agua para la irrigación y vi) la nutrición vegetal, fertilización y las interrelaciones del agua, el suelo y las plantas. 

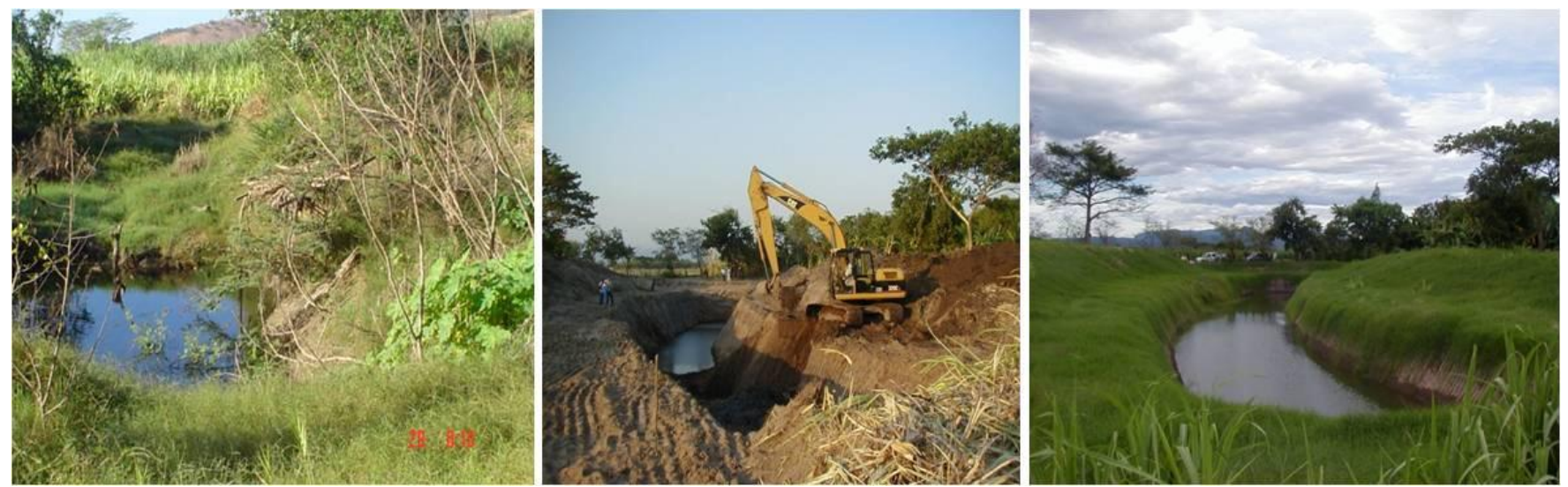

Figura 7. Un ejemplo de las estructuras de captura, conservación y acceso de agua para irrigación en Marcovia, cuenca baja río Choluteca, Honduras, (DSEA, 2005).

El proyecto promovió el mejoramiento de los marcos políticos y legales para el manejo del agua a través de la gobernanza local. Se fortaleció la capacidad legislativa y administrativa para el manejo del agua con la participación activa de los actores locales en el enlace de los problemas y la implementación de las acciones. Se implementaron pequeños proyectos que detonaron el logro de otros indicadores del proyecto.

Al final del proyecto se habían construido 31 sistemas mejorados de agua, incluidos cuatro pozos, que beneficiaban directamente a 3,610 familias. El proyecto también incluyó la revisión y el incremento de las tarifas de agua a valores entre 50 y $200 \%$. También se fortaleció la habilidad de los gobiernos locales y las comunidades para incorporar los sistemas de pago por servicios ambientales para proteger las fuentes de agua. Además, se estudió la cuenca bajo del rio Choluteca con el propósito de servir como herramientas de toma de decisión. Los estudios más relevantes incluyeron estos temas: (DSEA, 2005):

- Las condiciones biofísicas y socioeconómicas y el análisis de la vulnerabilidad a nivel de la subcuenca

- Los medios de vida y el uso del agua en la cuenca baja del río Choluteca

- Las especies arbóreas comerciales en el sur de Honduras

- Estudio general de los suelos de la cuenca baja del río Choluteca
- Zonificación ecológica de la cuenca baja de río Choluteca

- Catálogo de Proyectos: Un año de acciones en la cuenca baja

- Medios de vida y uso del agua en la cuenca baja del río Choluteca

- Atlas interactivo de la subcuenca de los ríos Choluteca y Negro

- Modelos locales de servicios ambientales: La experiencia de la cuenca baja de los ríos Choluteca y Negro.

\section{Manejo Integrado de Recursos Ambientales} (MIRA/USAID). Este proyecto se desarrolló entre el 2005 y 2007 como un subcontrato con la International Resources Group (IRG/Washington)/USAID). El mismo fue liderado por el Ing. Robert Walle, bajo la administración de la Decanatura de Proyección. Zamorano participó, durante los primeros dos años, en los temas de planificación del manejo de cuencas, el monitoreo de la calidad del agua y el fortalecimiento de la educación ambiental en la educación superior de Honduras. Se elaboraron planes de manejo de varias microcuencas nacionales mediante la aplicación de una metodología (Figura 8) similar a la desarrollada con el Proyecto Zamorano/FUPAD en la Libertad, Comayagua (DSEA, 2000). También se implementaron la capacitación y las acciones de protección y restauración ambiental en dichas microcuencas. 


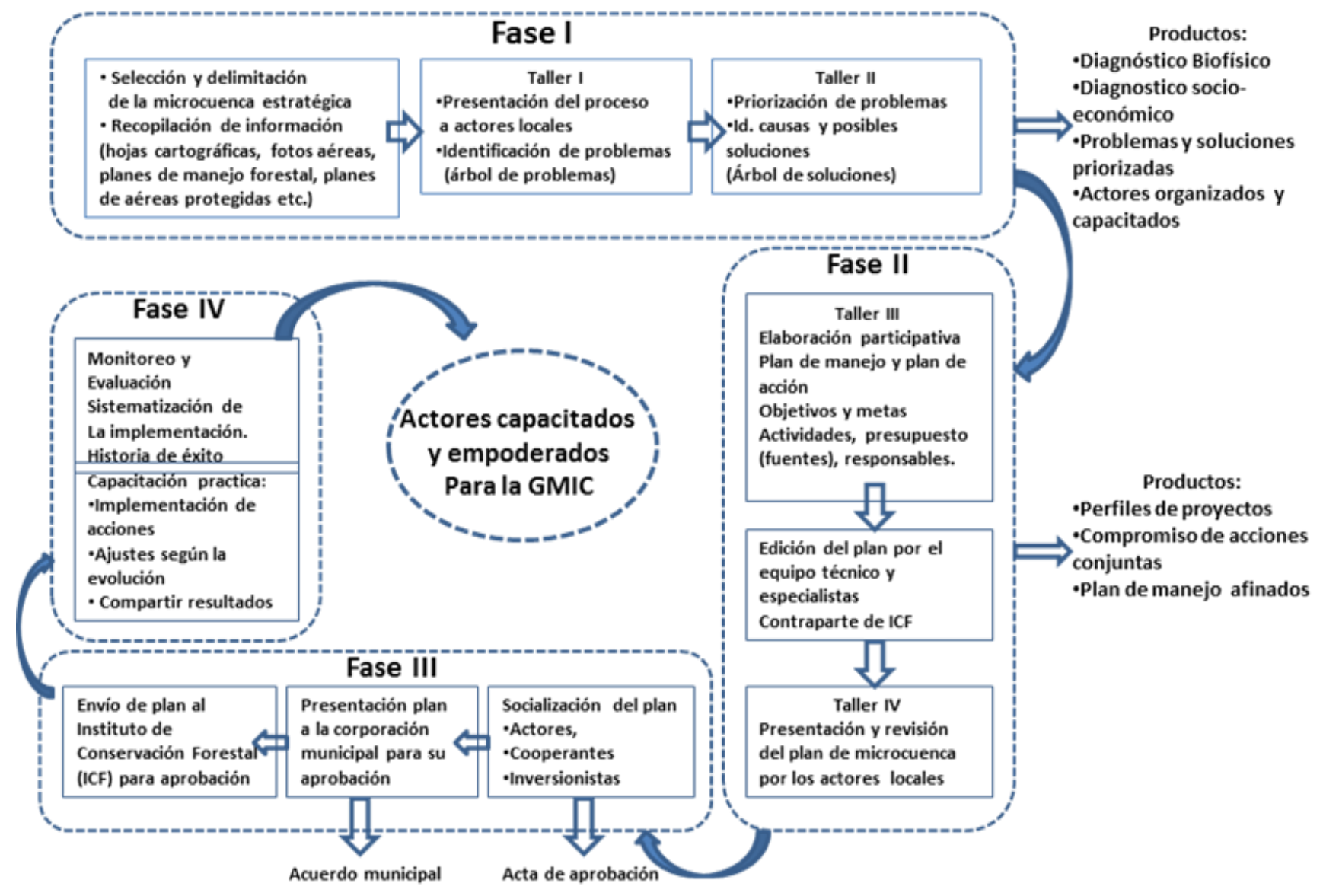

Figura 8. Modelo de planificación participativa para la elaboración de planes de gestión y manejo de microcuencas (GMIC) aplicado en el Proyecto MIRA Zamorano/IRG/USAID. Adaptado de la metodología desarrollada por el Proyecto Zamorano/FUPAD/USAID en La Libertad, Comayagua (DSEA, 2000; IRG/Zamorano/USAID, 2006).

Proyecto Iniciativa del Yeguare (Fundación W.K. Kellogg). Fue liderado por el Ing. Carlos Ardón, duró cuatro años y cubrió los municipios de San Antonio de Oriente y Villa de San Francisco en el departamento de Francisco Morazán, y Yuscarán, Morocelí y Güinope en el departamento de El Paraíso (DSEA, 2008). El proyecto se basó principalmente en la Teoría de Cambio promovida por la Fundación W.K. Kellogg que se enfocó en la atención al joven y en los aspectos del capital humano, productivo, ambiental y social.

Los componentes del proyecto incluyeron: Apoyo a los microempresarios y pequeños productores en el mejoramiento de las actividades productivas, la promoción del riego eficiente, el procesado del café, el apoyo a las microempresas de turismo, el desarrollo y la formación integral de la juventud para su inserción laboral. Los beneficiarios del proyecto fueron los habitantes de las comunidades en las que se implementaron las actividades y proyectos de desarrollo económico y social. El proyecto ejecuto más de 60 pequeñas inversiones entre ellas: apoyo al mejoramiento de la infraestructura, equipamiento y la capacitación de microempresarios del sector productivo y turístico de la región, la conformación de los grupos juveniles y redes de juntas de agua, entre otros (Burbano 2011). 
Desarrollo del Capital Humano en Manejo de Cuencas y Recursos Hídricos. Además de la formación práctica de los miembros de las comunidades y personal técnico de los gobiernos locales a través de su participación en talleres y la implementación de acciones de los programas y proyectos, Zamorano, en coordinación con sus aliados nacionales e internacionales, ha desarrollo cursos de formación técnicocientífica para profesionales ligados al manejo de cuencas y los recursos hídricos. Entre estas capacitaciones están el Curso internacional de manejo integrado y sostenible de cuencas hidrográfica ( 1 y 2$)$, Diplomado Regional de Recursos Hídricos (1 y 2) que han capacitado personal técnico de entidades públicas, privadas y no gubernamentales de las Américas.

Curso Internacional de Manejo Integrado de Cuencas. Este curso fue coordinado en dos ocasiones por el Dr. Michael Lee (ex profesor de manejo de cuencas de Zamorano 1994-1996). Participaron profesionales de más de diez países de las Américas y El Caribe (Figura 9). El curso incluyó temas como la introducción al manejo integral de cuencas, la hidrología y los procesos biofísicos en las cuencas, problemas en las cuencas, calidad y cantidad de agua, técnicas de reconocimiento y mapeo de cuencas (delimitación y clasificación de cuencas, cartografía, uso de sistemas de información geográfico). Además, se incluyeron los temas de los bosques nublados y su importancia hidrológica, análisis de actores, análisis socioeconómico, elaboración de planes de manejo y la protección de las cuencas, políticas, normas y leyes.

El primer Diplomado Regional de Manejo Integrado de Recursos Hídricos se desarrolló en alianza con la Universidad de Nuevo México en el 2003-2004, fue financiado por The American Liaison Office (ALO)/USAID y aportes institucionales de la Universidad de Nuevo México y Zamorano. La Coordinación estuvo a cargo del Dr. Michael Campana por parte de la Universidad de Nuevo México, Estados Unidos y el Dr. Luis Caballero de Zamorano. En el diplomado participaron 28 profesionales de la ingeniería y licenciados, entre ellos gerentes y técnicos de empresas de agua, técnicos del sector público, privado y ONG. Ellos provenían principalmente de Honduras, Guatemala y España. Dicho diplomado se desarrolló en 240 horas de instrucción teórico práctico e incluyó los temas: foro regional los recursos hídricos desafíos y oportunidades, hidrología básica, mediciones hidrológicas, agua subterránea, calidad de agua, planificación de recursos hídricos, uso de SIG y sensores remotos, análisis de sistemas de agua rural, economía del agua, manejo de microcuencas y políticas de agua e instituciones.

Diplomado PREVDA. El segundo Diplomado Regional de Gestión Integrada de Recursos Hídricos (GIRH) se desarrolló en el marco del Programa Regional de Reducción de Vulnerabilidad y Degradación Ambiental en Centro América, (PREVDA), con fondos de la Unión Europea (DSEA, 2009). La coordinación estuvo a cargo del Dr. Raúl Zelaya y la Ing. Erika Tenorio de DESEA. El propósito fue promover, desde el entrenamiento académico, una visión holística del recurso hídrico que lleve a la generación de estrategias efectivas de manejo sostenible en las cuencas hidrográficas. El diplomado fue de 216 horas de instrucción teórico práctico y participaron 62 técnicos y profesionales de seis países de Centro América provenientes de alcaldías, secretarías y ministerios de ambiente y de salud pública, universidades, entidades prestadoras de servicio de agua potable e institutos nacionales de energía. El diplomado fue impartido de forma presencial por 10 profesores de Zamorano bajo la metodología de Aprender-Haciendo en los seis países de Américaa Central durante 10 meses (Figura 10). Así, Zamorano formó alianzas con entidades educativas regional y se consolidó como una entidad formadora en la promoción de una gestión integrada de los recursos hídricos (DSEA, 2009).

\section{Investigaciones Realizadas en Apoyo a la Gestión de Cuencas y Recursos Hídricos}

La educación, la investigación y la proyección de Zamorano en manejo de cuencas y recursos hídricos comienzan en 1993 en forma sistemática con la incorporación del Dr. Michael Lee como profesor de manejo de cuencas del recién formado Departamento de Recursos Naturales y Conservación Biológica. El Dr. Lee laboró de 1994 a 1996 e instaló la primera estación de medición de caudal en el río Yeguare, equipada con un "Steven water level recorder", la cual 
fue destruida por el huracán Mitch en 1998. El Dr. Lee también instaló una red de 10 pluviómetros de lectura manual en la cuenca del río Yeguare y 10 pozos de monitoreo de agua subterránea, como parte de una tesis de doctorado del Ing. Tim Barlett, de origen inglés. Lastimosamente, de esta investigación no se tienen los datos ni las publicaciones finales. El Dr. Lee lideró los primeros esfuerzos de proyección con el apoyo de USAID con el proyecto "Global Sustainable
Agriculture and Natural Resources Management Program". Desde 1994 hasta el 2012 se han realizado muchas investigaciones de pregrado de los estudiantes del ahora Departamento de Ambiente y Desarrollo (DAD), asesorados por sus profesores. Estas investigaciones contribuyeron al conocimiento del estado de los recursos naturales, al diagnóstico, la planificación, implementación, monitoreo y evaluación del manejo de cuencas en América Central.
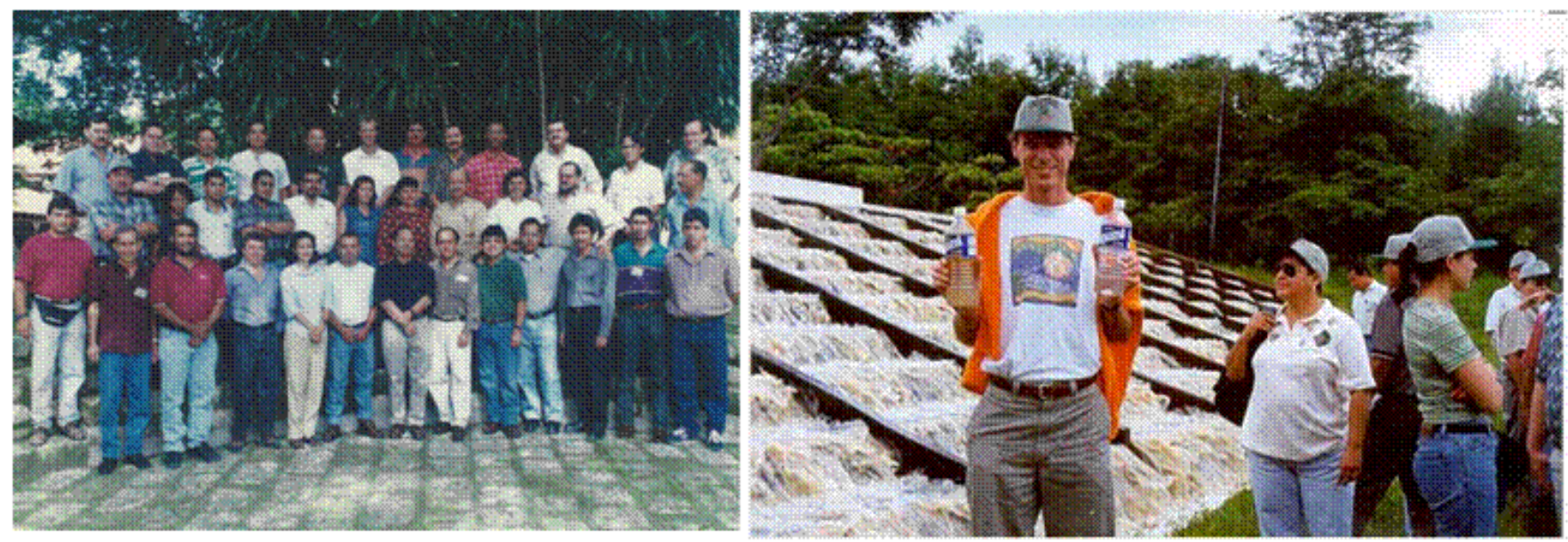

Figura 9. Participantes (izquierda) en el II Curso Internacional de Manejo Integrado de Cuencas (MIC-1999) provenientes de 10 países, desarrollado en coordinación con el Dr. Michael Lee (derecha gira al SANAA). Por Zamorano coordinó el Ing. Nelson Villatoro y Luis Caballero.
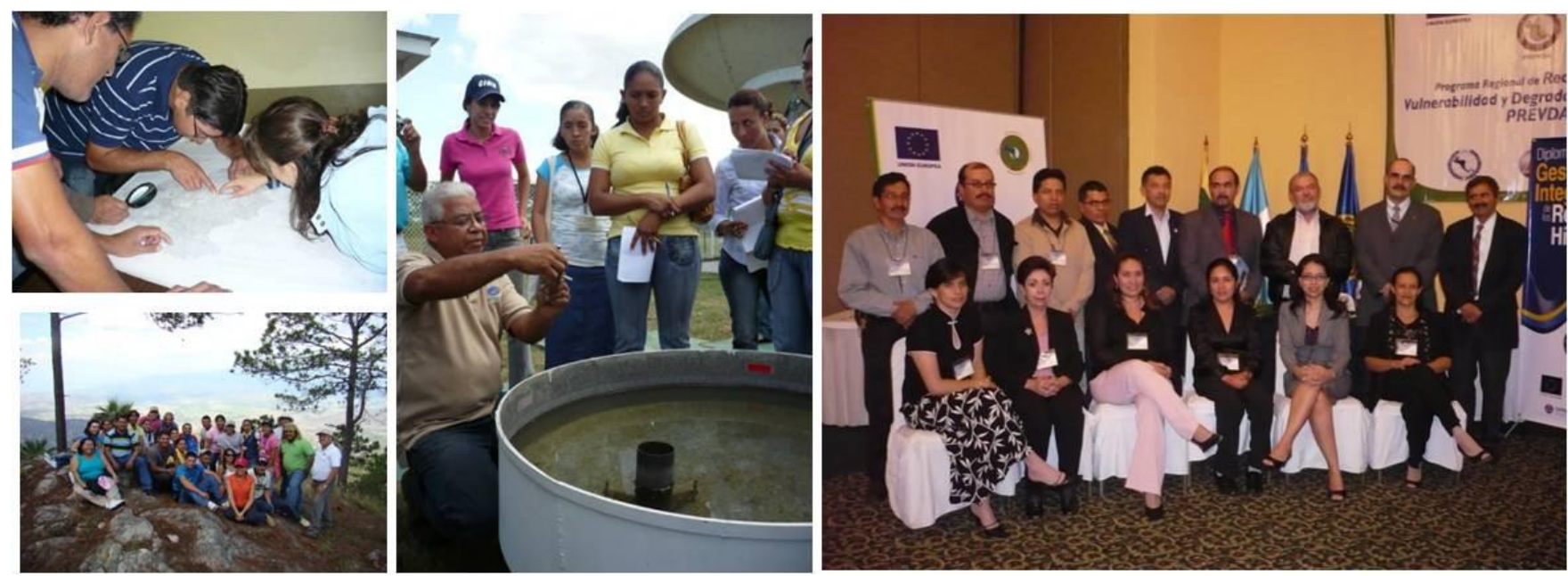

Figura 10. Ejemplos de capacitación teórico/práctica con laboratorios y giras de campo, y la ceremonia de cierre del Diplomado con autoridades del Programa PREVDA y los coordinadores Ing. Erika Tenorio y Dr. Raul Zelaya (DSEA 2009). 
La instalación de microcuencas experimentales para la investigación hidrológica en Zamorano comenzó en el 2003 con la construcción del primer vertedero tipo "v-notch" en las microcuencas El Capiro y El Zapotillo, Güinope, El Paraíso (Figura 11). Estas estaciones de monitoreo de caudal fueron construidos con fondos del consorcio de Manejo Integral de Suelos MIS/CIAT, liderado por el Dr. Manuel Ayarza. Los estudios de pregrado de estudiantes de Zamorano se enfocaron en la caracterización y mapeo de suelos y fertilidad (Garcia Puentes, 2001; Romero Melgar, 2003), estudio de relaciones precipitación-intercepción-escorrentía (Donaire Ramos, 2002), costo beneficio de tres sistemas productivos (Hernández Carvajal, 2002), calidad de agua y transporte de nutrientes (Vega Núñez, 2000; Soliz Nagatoshi, 2005), potencial de captura de los suelos (Martinez Martínez, 2008). Otras tesis se enfocaron en la evaluación de la calidad del agua evaluando los macro-invertebrados acuáticos (Orellana Zelaya, 2003), la dinámica hídrica y los usos del agua humano y para riego (Sabillon Garay, 2005), la caracterización biofísica y socioeconómica de los productores y la elaboración de planes de manejo de microcuencas (Ramirez Rosa, 1998, Rodriguez Tablas, 1999; Medina Herrera, 2001). Las investigaciones sirvieron para implementar los proyectos de manejo de cuencas subsiguientes y para la implementación de planes de manejo de dichas microcuencas.

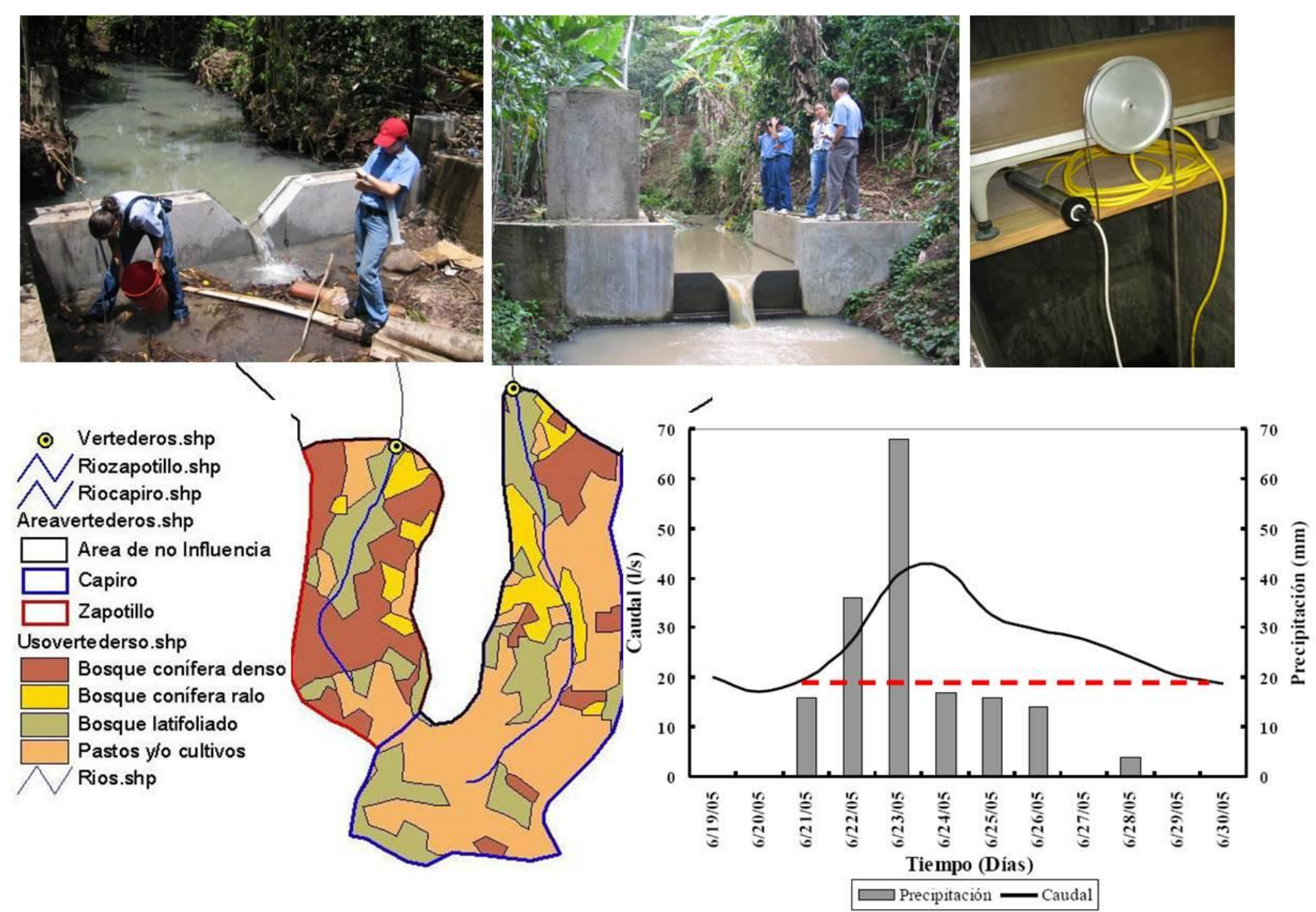

Figura 11. Investigación hidrológica en cuencas pareadas desarrollada con estudiantes de Zamorano (foto izquierda y centro). Microcuenca experimental Capiro-Zapotillo, Güinope, El Paraíso, 2003-2005. Mapa de uso del suelo y ejemplo de hidrograma (abajo). 
El Ing. Luis Caballero, estudiante de doctorado de la Universidad de Cornell, presentó en el 2007 la propuesta de investigación titulada: Investigando los efectos de los cambios en el uso de la tierra y clima en la hidrología de los bosques nublados, La Tigra National Park, Honduras al programa "Canon National Parks Science Scholar Program”, el objetivo era avanzar la investigación realizada en Capiro-Zapotillo. $\mathrm{Su}$ propuesta salió entre las ocho favorecidas de las 168 presentadas provenientes de toda a la América a la Asociación Americana para el Avance de la Ciencia (AAAS) (www.businesswire.com, 2007). Así, en el
2008 se diseñó y construyó la primera cuenca experimental en Honduras, y la segunda en Centro América, compuesta de cinco estaciones hidrométricas (Figura 12 y 13). El propósito fue contribuir al conocimiento de la hidrología de los bosques nublados, importantes fuentes de agua en el trópico y el subtrópico, y así promover la protección de los parques nacionales. El Ing. Caballero también recibió una beca de la Organización de Estados Americanos (OEA), y asistencia financiera de la Universidad de Cornell/USDA mediante un "teaching and research assistanship" y apoyo logístico de Zamorano.

\section{La Tigra Experimental Watershed, La Tigra National Park, Honduras. Cornell/Zamorano University Funding: CANON-NPS-AAAS/OAS/USDA-Cornell.}

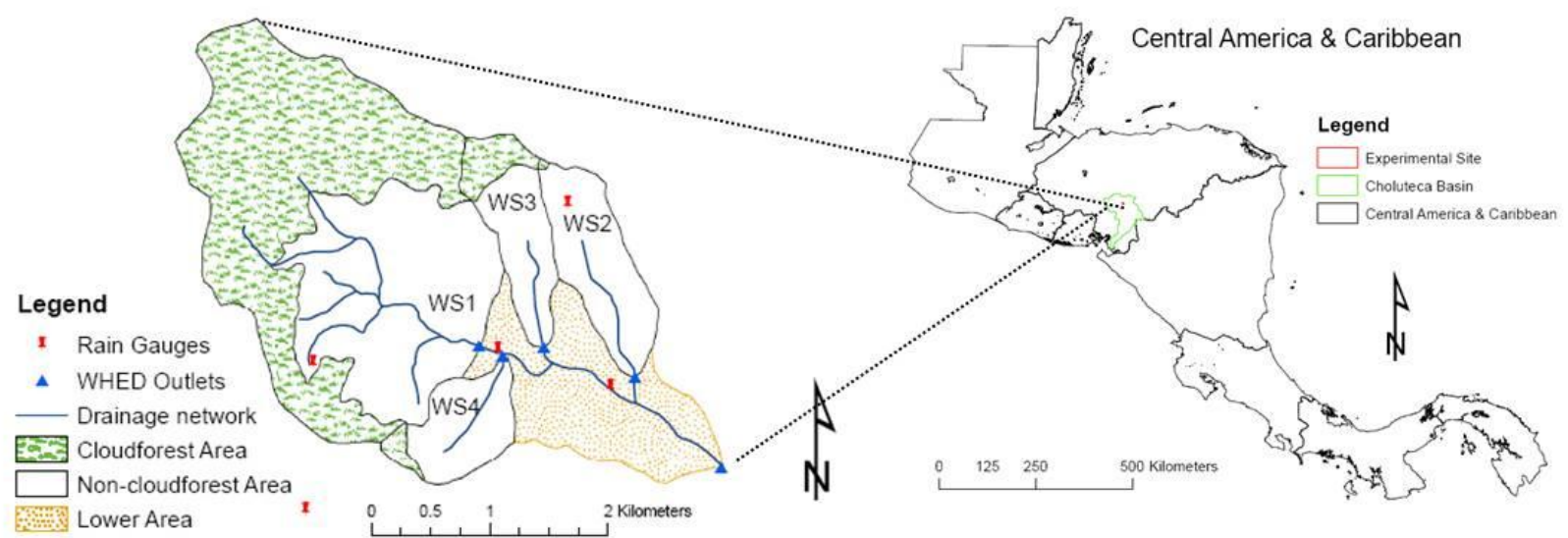

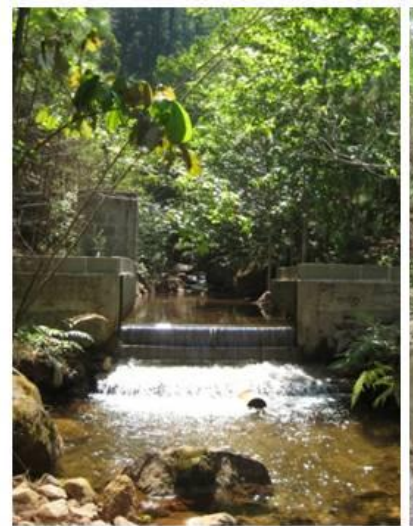

WS1

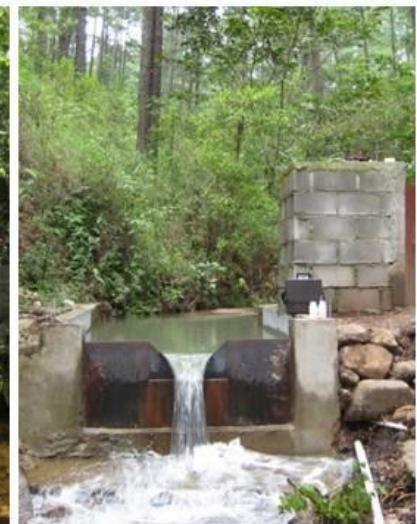

WS2

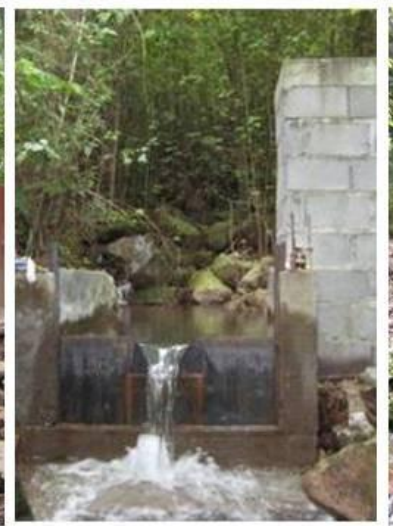

WS3

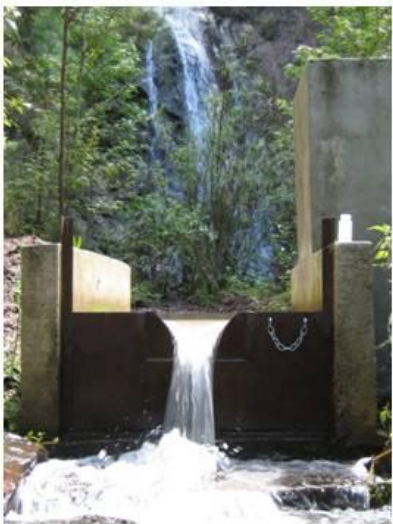

WS4

Figura 12. La microcuenca experimental La Tigra, primera cuenca experimental en Honduras y la segunda en Centro América, creada para realizar investigación hidrológica en el bosque nublado (Caballero et al., 2012). 

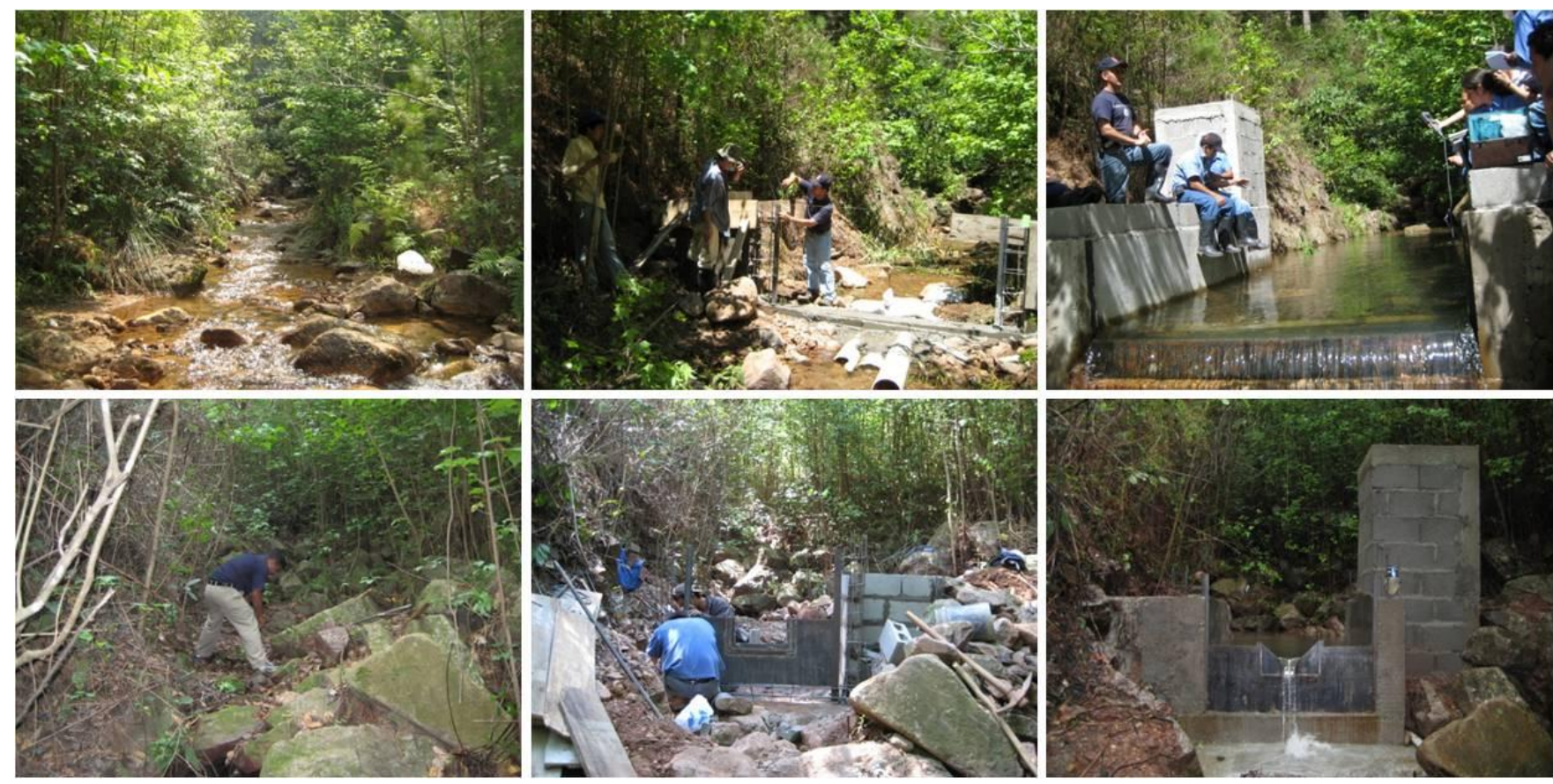

Figure 13. Vista del proceso de construcción de dos de los cuatro vertederos construidos. Tipo rectangular (WS1) arriba y tipo v-notch (WS3) abajo. Cuenca Experimental La Tigra, Honduras (Caballero, 2009).

Los estudiantes de Zamorano, además de visitar y dar charlas sobre hidrología en la cuenca experimental La Tigra, han contribuido con tesis a su conocimiento (Goyzueta Altamirano, 2009, Lavaire Cruz y Fiallos Lopez, 2010, Barinas Vizcaino, 2008, Pech Tillett, 2011). Los estudios de tesis de doctorado del Dr. Luis Caballero, en la Universidad de Cornell (2006-2011), culminaron con tres publicaciones científicas en revistas de prestigio internacional (Caballero, 2011, Caballero et al. 2013). En 2013, el estudiante de doctorado Christian Guzman de la Universidad de Cornell, estará modelando la producción de sedimentos en esta cuenca. Este estudio estará apoyado con fondos del Consorcio de Universidades para el Avance de la Ciencia Hidrológica (CUAHSI) (Pathfinder Fellowships Awardees 2012).

A partir del 2011, se inició la gestión de fondos para el diseño y construcción de la microcuenca experimental Santa Inés en las cercanías del campus de la Escuela Agrícola Panamericana, con fines educativos, de investigación y proyección. Además de ser de alta prioridad hídrica, la microcuenca Santa Inés reúne todas las condiciones físicas, hídricas y sociales para convertirse en un centro experimental de gestión integrada de cuencas y recursos hídricos (Caballero, 1995). Una serie de visitas de técnicos, autoridades de Zamorano y aliados se han realizado a la microcuenca (Figura 14), misma que ya fue seleccionada para ese propósito en 1995, por el estudio de tesis de maestría en Colorado State University, Estados Unidos, por el Ing. Luis Caballero.

Esta microcuenca experimental tendrá estaciones meteorológicas con transmisión de datos a tiempo real, al menos tres estaciones hidrométricas para monitoreo de caudales con resolución de minutos, sistemas de colección de muestras de agua automática y sensores de humedad del suelo, calidad del agua y transporte de sedimentos. El plan incluye el establecimiento de una finca demostrativa para producción agroforestal con café de altura, con técnicas de producción asociado con maderas, frutales y conservación de suelos, beneficiado limpio de café, producción de biogás y otras tecnologías. Todo lo anterior es para fortalecer la formación técnica-científica y académica de los 
futuros Ingenieros Ambientales y Agrónomos en el manejo de cuencas y la prevencion y mitigacion de los impactos del cambio climático. La meta es que la microcuenca Santa Inés se convierta en un laboratorio vivo para la Gestión y Manejo Integral de Cuencas (GMIC), así como gestión eficiente del recurso hídrico, prevención y manejo de conflictos asociados al agua y la preparacio de los usuarios del recurso agua ante los efectos del cambio climático global.

Entre los avances por medio de prácticas de los estudiantes y estudios de tesis hasta el 2012 están: muestreos semanales de caudal por el módulo de riegos, caracterización hidrológica, potencial hídrico y balance hídrico de la microcuenca Santa Inés (Garcia Ramos, 1993; Huezo Sanchez, 2011), potencial para establecer una cuenca experimental en Santa Inés (Caballero, 1995), caracterización y avance de la frontera agrícola (Barahona Flores, 1997), diagnósticos socio-económicos (Tuchan Ramos y Diaz
Rueda, 2011), estudio edafológico para la clasificación y mapeo de suelos (Acosta Velasquez y Kucharsky Lezama, 2012). En el 2011 se formalizó una alianza con Colorado State University para realizar estudios de modelación hidrológica y desarrollar proyectos conjuntos en gestión y manejo de cuencas y de los recursos hídricos. Así mismo, se trabaja en el 2013 para formalizar una alianza (memorándum de entendimiento) con la Universidad de Cornell y Agua Para El Pueblo. Mediante esta cooperación, se construirá una planta de tratamiento de agua con fines de investigación, desarrollo tecnológico y entrenamiento de los futuros operadores de estas plantas Centro América. Esta planta también proveería del servicio de agua a las comunidades de Santa Inés y Santa Rosa, cumpliendo los estándares o normas técnicas de calidad para agua potable.
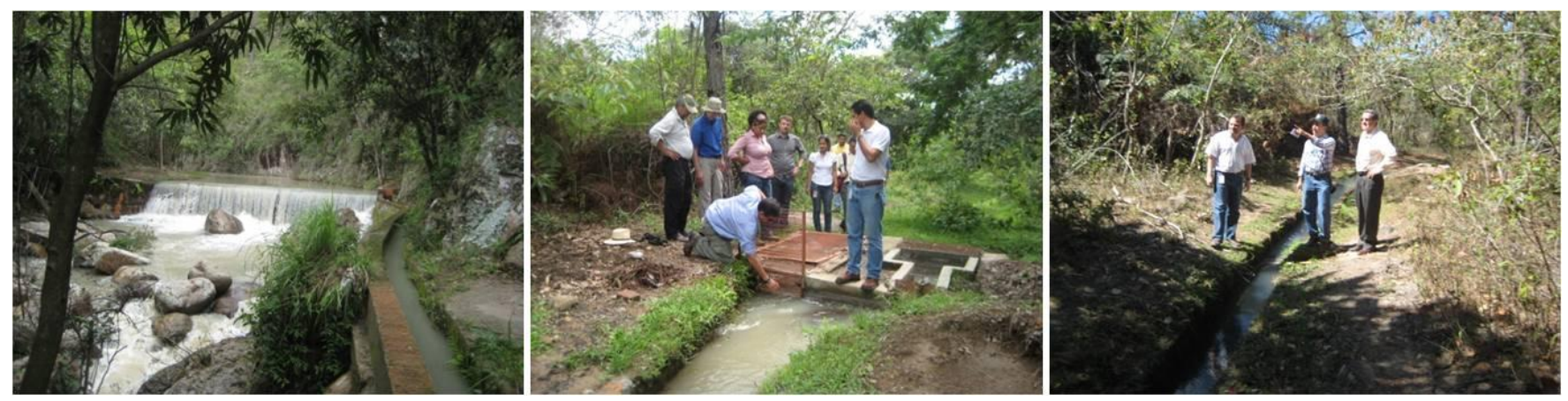

Figura 14. Visitas de técnicos y de autoridades de Zamorano a la microcuenca Santa Inés para definir y planificar las inversiones y protección de la microcuenca. Obra de la toma actual (izquierda), visita de la Universidad de Cornell (centro), visita del rector Dr. Roberto Cuevas García y personal técnico de Zamorano (derecha).

Agradecimientos. Se agradecen las conversaciones y aportes del Dr. George Pilz, Ing. Carlos Ardon, Ing. Erika Tenorio, Ing. Nelson Agudelo, Arq. Eduardo Aguilar por sus aportes específicos de los proyectos que lideraron. Especial agradecimiento a los técnicos de los proyectos ejecutados en los últimos 18 años: Ing. Robert Walle y Olman Rivera, Ing. Erika Tenorio, Ing. Marco Granadino, a Rony Estrada y Nelson Gamero, técnicos muy capaces y especiales, a Manuel Padilla, Francisco Paredes, y otros que se escapan.
Para la investigación en el Parque Nacional La Tigra se agradece el apoyo de la Ing. Tenorio en la instalación de pluviómetros, a la Ing. Gloria de Gaugel por el mapeo de suelos, a Reiniery Ortiz, Yesica de Ortiz y Francisco Cárcamo por el apoyo logístico y la toma y procesado de muestras de agua. A los Ing. Marcelo Goyzueta Altamirano, Tito Lavaire Cruz, Elwin E. Fiallos Lopez y Yanira Pech Tillett por sus trabajos de investigación en apoyo al estudio en el Parque Nacional La Tigra. Al Dr. Hans Kammerbauer 
y Jose Manuel Gonzales de CATIE por su apoyo en la selección de los sitios para la investigación, a AMITIGRA y su personal de campo y la Municipalidad de Valle de Ángeles por aprobar y apoyar esta investigación.

Agradecimiento muy especial al Dr. Tammo Steenhuis del Departamento de Ingeniería Biológica y Ambiental de Cornell, por brindarme la oportunidad de aprender con él y ser mi mentor, al Programa Canon National Parks Science Scholar Program/AAAS-LASPAU por financiar la investigación y la USDA, OEA y la Universidad de Cornell por financiar mis estudios en la Universidad de Cornell, en especial a la Dra. Francille Firebaugh, Dr. Terry Tucker, Dr. Steve DeGloria y David R Lee. En Zamorano al Dr. Kenneth Hoadley, exrector de Zamorano, por brindarme el permiso para estudiar, a la Dra. Ana Margoth de Ardrews, Dr. Keith Andrews, Dr. Mario Contreras y Dr. George Pilz por animarme a proseguir mis metas.

Se agradece a los directores de DSEA, Licda. Mayra Falck y al Ing. Arie Sanders por su apoyo, así como a todo el equipo técnico, docente $\mathrm{y}$ administrativo de DSEA que de alguna manera estuvo involucrado y fue un participante activo en los proyectos ejecutados desde 1996 hasta la fecha.

Un agradecimiento muy especial al Ing. Peter Doyle por sus enseñanzas y liderazgo. La decisión de quedarme en Zamorano, durante el inicio de su administración, fue la mejor decisión; pues he recibido mucha recompensa académica y de crecimiento profesional. Especial agradecimiento a los productores, juntas de agua de las comunidades y gobiernos locales con quienes trabajamos juntos y nos enseñaron a aterrizar nuestras intervenciones. Al Dr. Abelino Pitty por animarme a escribir, por sus comentarios y tiempo dedicado a editar de este articulo.

Un agradecimiento especial a la USAID/ Honduras, en especial al Ing. Peter Hearne, de la Oficina Agricultura y Recursos Naturales (ANRO) por creer en nosotros y en Zamorano como un aliado para ejecutar sus proyectos y lograr los objetivos de la misión de USAID en nuestros países.

Finalmente, un profundo agradecimiento a mi familia, por soportar la ausencia en el hogar al dedicar jornadas largas a la supervisión de los proyectos.

\section{Literatura Citada}

Acosta Velasquez, A.F. y Kucharsky Lezama O.A. 2012. Estudio edafológico y de cobertura para la modelación hidrológica con el modelo SWAT de la microcuenca Santa Inés, Honduras. Tesis de Ingeniería en Desarrollo Socioeconómico y Ambiente. Escuela Agrícola Panamericana, Zamorano, Honduras. 35 p.

Aguilar, E. y E. Ramirez. 2000. Programa de Desarrollo de la Región del Yeguare (Resumen de acciones Proyecto UNIR). Escuela Agrícola Panamericana. Informe Técnico $35 \mathrm{p}$.

Barahona Flores, F.V. 1997. Caracterización del avance de la frontera agrícola en las zonas de recarga hídrica que abastecen a Lavanderos y Güinope, El Paraíso, Honduras. Tesis de Ingeniería en Departamento de Recursos Naturales y Conservación Biológica. Escuela Agrícola Panamericana, Zamorano, Honduras. 55 p.

Barinas Vizcaino, M. 2008. Caracterización de las comunidades de macro invertebrados acuáticos de la microcuenca El Carrizal, Parque Nacional La Tigra, Honduras. Tesis de Ingeniería en Desarrollo Socioeconómico y Ambiente. Escuela Agrícola Panamericana, Zamorano, Honduras. 43 p.

Burbano, V.M. D. 2011. Evaluación piloto de la participación de microempresarias del sector turismo en el Valle del Yeguare. Tesis de Ingeniería en Desarrollo Socioeconómico y Ambiente. Escuela Agrícola Panamericana, Zamorano, Honduras. 50 p.

Caballero, L.A. 1995. Guidelines for developing a small experimental watershed for research and educational purposes, Pan-American School of Agriculture Honduras Central America. Tesis de maestría, Colorado State University. 65 p.

Caballero, L.A. 2007. Human impact on hydrologic processes in headwater cloud-forest catchments in La Tigra National Park and Guinope Mountains, Honduras. Dissertation research proposal presented to Canon National Parks Science Scholars Program. Biological \& Environmental Engineering Department, Cornell University. Ithaca, New York. 10 p.

Caballero, L.A. 2009. Midterm report to Canon National Parks Science Scholars Program. Biological and Environmental Engineering Department, Cornell University, Ithaca, New York. 11 p.

Caballero, L.A. 2010. http://zamonews.zamorano.edu/ noticias/10/mayo/Esp/diaagua.html. Agua fuente de vida y de riqueza. 
Caballero, L.A. 2012. Hydrology, hydrochemistry, and implication for water supply of a cloud forest in Central America. Doctoral Dissertation Thesis, Cornell University, Ithaca, New York. 143 p.

Caballero, L.A., A. Rimmer, Z.M. Easton y T.S. Steenhuis. 2012. Rainfall runoff relationships for a cloud forest watershed in Central America: Implications for water resource engineering. Journal of the American Water Resources Association 48:1022-1031.

Caballero, L.A. Easton, Z.M, Richards, B.K., Steenhuis, T.S. 2013. Evaluating the bio-hydrological impact of a cloud forest in Central America using a semidistributed water balance model. Journal of Hydrology and Hydromechanics 61:9-20.

Diaz Rueda, L.N. y Tuchan Ramos, K.M. 2011. Análisis de actores sobre el manejo colaborativo de la Microcuenaca Santa Inés, Honduras. Tesis de Ingeniería en Desarrollo Socioeconómico y Ambiente. Escuela Agrícola Panamericana, Zamorano, Honduras. $27 \mathrm{p}$.

Donaire Ramos, G.E. 2002. Establecimiento de una red de monitoreo hidrológico en tres tipos de cobertura en la microcuenca El Zapotillo, Güinope, El Paraíso, Honduras. Tesis de Ingeniería en Desarrollo Socioeconómico y Ambiente. Escuela Agrícola Panamericana, Zamorano, Honduras. 38 p.

DSEA (Carrera de Desarrollo Socioeconómico y Ambiente). 2000. Plan de Manejo de las microcuencas de los ríos Frio y Salitroso, La Libertad Comayagua, Honduras. Escuela Agrícola Panamericana. Informe Técnico 54 p.

DSEA (Carrera de Desarrollo Socioeconómico y Ambiente). 2001. Proyecto "Watershed rehabilitation and improved natural resources management in the upper Choluteca watershed. Escuela Agrícola Panamericana. Final technical and financial report. $41 \mathrm{p}$.

DSEA (Carrera de Desarrollo Socioeconómico y Ambiente). 2005. "Water Resources Management in the Choluteca and Rio Negro Basins" USAID/Honduras Cooperative Agrement \# 522-A-00-03-000420-0. Escuela Agrícola Panamericana. Informe técnico final 29p

DSEA (Carrera de Desarrollo Socioeconómico y Ambiente). 2008. Iniciativa del Yeguare, Trabajo conjunto para el desarrollo de la región. Escuela Agrícola Panamericana. Informe técnico final $29 \mathrm{p}$.

DSEA (Carrera de Desarrollo Socioeconómico y Ambiente). 2009. Proyecto PREVDA. Diplomado en Gestión Integrada de Recursos Hídricos. Escuela Agrícola Panamericana, Informe técnico final 66 p.
Garcia Puentes, L.E. 2001. Estudio de línea base de suelos en un sitio de referencia en la microcuenca de El Zapotillo, Güinope, Honduras. Tesis de Ingeniería en Desarrollo Socioeconómico y Ambiente. Escuela Agrícola Panamericana, Zamorano, Honduras. 50 p.

Goyzueta, Altamirano, M., 2009. Caracterización hidrológica de la quebrada el Carrizal, Parque Nacional La Tigra. Honduras. Tesis de Ingeniería en Desarrollo Socioeconómico y Ambiente. Escuela Agrícola Panamericana, Zamorano, Honduras. 50 p.

Hernández Carbajal, J. I. 2003. Comparación costo beneficio entre sistemas productivos y su relación con el estado nutricional de los suelos en tres micro drenajes en la microcuenca El Zapotillo, Güinope, Honduras. Tesis de Ingeniería en Desarrollo Socioeconómico y Ambiente. Escuela Agrícola Panamericana, Zamorano, Honduras. 89 p.

Huezo Sanchez, L. A. 2011. Caracterización hidrológica y balance hídrico de la microcuenca Santa Inés, Honduras. Tesis de Ingeniería en Desarrollo Socioeconómico y Ambiente. Escuela Agrícola Panamericana, Zamorano, Honduras. $25 \mathrm{p}$

IRG/DSEA (International Resources Group/Carrera de Desarrollo Socioeconómico y Ambiente). 2006. Proyecto Manejo Integrado de Recursos Ambientales (MIRA/USAID). Plan de Manejo de Recursos Naturales en la Microcuenca Quebrada El Zapote. Un proceso participativo de éxito. Municipio de Teupasenti, Departamento de El Paraíso, Honduras. $108 \mathrm{p}$.

Levaire, Cruz. T. y Fiallos, Lopez. E. E. 2010. Potencial de captura de agua de los suelos de la microcuenca El Carrizal, Parque Nacional La Tigra, Francisco Morazán, Honduras. Tesis de Ingeniería en Desarrollo Socioeconómico y Ambiente. Escuela Agrícola Panamericana, Zamorano, Honduras. 48 p.

Martínez Martínez, M. C. 2008. Potencial de captura de agua en los suelos de capiro y zapotillo, Guinope, El paraíso, Honduras. Tesis de Ingeniería en Desarrollo Socioeconómico y Ambiente. Escuela Agrícola Panamericana, Zamorano, Honduras. 39 p.

Medina Herrera, P. J. 2001. Plan de manejo participativo orientado a la protección y conservación del recurso agua en la microcuenca El Zapotillo, Guinope, El Paraíso, Honduras. Tesis de Ingeniería en Desarrollo Socioeconómico y Ambiente. Escuela Agrícola Panamericana, Zamorano, Honduras. 98 p. 
Orellana Zelaya A.C. 2003. Línea base de la calidad y cantidad de agua en la microcuenca El Zapotillo, Guinope, El Paraíso, Honduras. Tesis de Ingeniería en Desarrollo Socioeconómico y Ambiente. Escuela Agrícola Panamericana Zamorano, Honduras. 77 p.

Pathfinder Fellowships 2012. http://www.cuahsi.org/2012Pathfinder.aspx

Pech Tillett. Y. 2011. Evaluación de Tasas de Escorrentía en Cuatro Microcuencas en el Parque Nacional La Tigra, Honduras. Tesis de Ingeniería en Desarrollo Socioeconómico y Ambiente. Escuela Agrícola Panamericana, Zamorano, Honduras. 50 p.

Ramirez Rosa, E.R. 1998. Caracterización biofísica de la microcuenca El Capiro, Municipio de Güinope, Departamento de El Paraíso, Honduras. Tesis de Ingeniería en Desarrollo Socioeconómico y Ambiente. Escuela Agrícola Panamericana, Zamorano, Honduras. $31 \mathrm{p}$.

Rodriguez Tablas, V.V. 1999. Caracterización y evaluación participativa de aspectos biofísicos y socioeconómicos de las microcuencas El Capiro y El Zapotillo, Guinope, El Paraíso. Tesis de Ingeniería en Desarrollo Socioeconómico y Ambiente. Escuela Agrícola Panamericana, Honduras. 89 p.
Sabillon Garay, D.M. 2005. El impacto de los sistemas de riego en los medios de vida sostenible de pequeños productores en las microcuencas de Capiro y El Zapotillo, Guinope, El Paraíso, Honduras. Tesis de Ingeniería en Desarrollo Socioeconómico y Ambiente. Escuela Agrícola Panamericana, Honduras. 41 p.

Soliz Nagatoshi, J. 2005. Análisis comparativo de la cantidad y calidad de agua en las microcuencas El Capiro y El Zapotillo, Güinope, El Paraíso, Honduras. Tesis de Ingeniería en Desarrollo Socioeconómico y Ambiente. Escuela Agrícola Panamericana, Honduras. $47 \mathrm{p}$.

Vega Núñez, J.M. 2001. Evaluación de la calidad, cantidad y fuentes de contaminación del agua de la microcuenca El Zapotillo. Tesis de Ingeniería en Desarrollo Socioeconómico y Ambiente. Escuela Agrícola Panamericana, Zamorano, Honduras. 50 p.

Walle R. 2004. Un Año de Trabajo para el Mejoramiento del Manejo de Recursos Hídricos en las Cuencas Río Choluteca y Negro: Un Catálogo de Obras Hechas por Zamorano. Informe técnico de Proyecto "Manejo del Agua en las Cuencas de los Ríos Choluteca y Negro" Zamorano-USAID.

Recibido para publicación el 14 de febrero de 2013. Aceptado para publicación el 14 de marzo de 2013. 